\title{
KOŃ TROJAŃSKI \\ Geneza, ewolucja oraz recepcja mitu w starożytności
}

Jakże pragnęłabym of laroweć Czcigodnemu Jub1latộl dar plóra zgodny z zakresein Jego zainteresowańl Cóz, k1edy nie pozwala na to zakres moich umiejętnośc1. Mam jednak nadzieje, te jako humantsta 1 starożytik przyjmie Ks.Prof. Andrzej Bober tych kilka uwag dotyczacych Jednego greckiego mitu. Mitu, który powstał u zarania kultury antycznej i nie tylico mocno tkwil do jej schyłku p ludzkiej świadomości inspirując poetów 1 artystów, lecz przetrial az do naszych czasów. Do poł. XX w. nazwa mitu budziła jeszcze zywe skoJarzenia szeroko wykorzystywane w literaturze pieknej, a czasam nawet w publicystyce. W ostatnim ówier ćwieczu mit, Jak wiele 1nnych, uległ zapomnieniu 1 zapewne obecnie porównante kogokolwiek do konia trojańskiego trafiłoby w próźnie. Jednak my, starozytnicy, bez mzględu na speojalizacje potrafimy jeszcze olqglo spotykać się na mspólnej płaszczyźnie, jaka jest znajomość kultury antyoznej, a przede wozystk1m 11teratury 1 sztuk1 starozytnej Grecj1 1 Hzym. Konfrontowanie źródel należcych do tych dwóch kategori1 daje niejednokrotnie clekawe wynik1. Ponizej bęuę sie posługiwaó ta właśnie metoda, aby rzucié śwlatło na genezo 1 ewolucje mitu, a takze na historlę jego odbioru wóznych okolicznościach historycznych.

Mit o drewnianym konlu podstepnie wprowadzonym do obleganego miasta nie występuje w literaturze starożtnej przed "Osyseja" 1 . i nalezy przypuszczać, że zostaz on wymyślony przez autora poematu. Hersja homerycka jest lcrótka 1 pełna niedomówień, o charakterze basniowym. Watek ten był autorowt po prostu potrzebny dla mozliwie przekonywującego wyjaśnienta przyczyn upadku Troi, a tym samya do przerzucenta pomostu między "Odyseją" a "Illadą".

Mit nie został wprowadzony do zadnego utworu nie zwizzanego z cyklem trojańskin. Moźna by co najwyzej doszukiwać się jego od-

1 Odyssea IV 271-289; VIII 492-515; XI 523-532. 
głosów w opowiadaniu Platona o Gygesie królu Lidil, który miał znaleź $w$ podziemnym grobowcu ogromnego konia z brazzu, pustego w B́rodku, z drzwiczkami woku. Otwarłszy drzwiczki znalazł Gyges w środku leżącego nagiego, martwego olbrzyma ${ }^{2}$. Ponlewaź jednak koń występujący w tym opowiadaniu jest z brązu, a nle z drewna, przeto sądze, ze Platona insplrował nie tyle mit, 1le brazowy pomnik konia trojańskiego na ateńskiej akropoli /por. nizej/.

W literaturze okresu Cesarstma lizymskiego mozna znaleźc próby racjonalistycznoj interpretacjl mitu, a poniewaz $1 \mathrm{ch}$ autorzy poworuja sie na "communis opinio", przeto nalezy rozumied, ze korzystali ze starszej literatury homerologlcznej, niewątplivie greckiej. Pliniusz ${ }^{3}$ i Pauzaniasz ${ }^{4}$ godnie trierdza, te koń trojański, to nic Innego jals machina oblężicza, przy ozyı Pliniusz precyzuje, ze byz to prototyp taranu do rozwalania bram za jego czasów zwanego "aries" /istotnie głowa taranu była ukształtowana na wzór głomy barana/. Znając tę interpretacje można zrozumieó dlaczego Werg111usz włozyz w usta Priama pytanio skierowane do Sinona, czy kó́ nie jest przypadkiem machina oblęznicza ${ }^{5}$. Autorzy rzymscy nie zdawall sobie oczywiście sprany, ze lch interpretacja jest rómile fantastyczna, Jak sam mit. W epoce oplaywanej przez Homera machiny obleznicze nie byzy jeszcze znane. Mozna natomiast ldąc tym śladem zastanowió sie, Jak1 wytwór rąk ludzk1ch, współczesny Homerow1, naprawde zalnspirował poete. Byl nim niewątpliwie okręt jako jedyna drewniana konstrukcja o dużych rozmiarach powszechnte znana 1 wykonywana wrecj1 okresie powstawania poematów homeryckich. Stąd tez "Odyse1" Epejos mystępuje jako budowniczy konia, nie zaś snycerz, lub ciesla. Dodajmy, ze poete zaingpirowá mogly dodatkowo zoomorficzne ozdoby okrętowych dziobów, np. Końska protome.

Zw1ęzłó́ć wersjl homeryckiej, wynikające etąd niejasności, a zarazem kluczowe znaczenie tego mitu dla powlazania "Odyse1" z "Illa-

2 Respublica II 359 D-360 B; Inaczej P.M.Schuhl, Le "cheval de Troie", "Revue Archéologique", Série 6,7/1936/ 186-188.

3 H1storia Naturalis VII 202.

4 Periegesis I 23,8.

5 Aeneis II 150. 
dą" sprawily, ze został on podchwycony 1 znacznie rozszerzony przez epigonów Homera, Leschesa $w$ "Małej Illadzie" 1 Arktinosa "Zagładzie Il1onu". Treść tych utworów znana jest tylko warysach, z dwóch pó́nych streszczeń Proklosa 1 Apollodorosa', a nadto tylko Proklos wyraźnte rozgranicza obu autorów 1 ich dzieła. Sądze, ze posługująo się analiza wyobrazeń starozytnych moźna uzupeznić owe streszczenia, zwłaszcza przypadku "Małej Illady". Do kwestil tej jeszcze wrócę, a na razie postaram się pprowadzić podstawowe ustalenia chronologlczne, czym źródła archeologiczne sa niezmiernie pomocne.

Przyjęliśmy wyżej, ze mit o drewnianym konlu został wymyślony samodzielnie przez autora "Odyse1". Datowante tego poematu waha sie od VIII do VII.W. W ostatnim trzydziestoleciu zostały jednak znalezione dwa przedmioty, które przynosza ustalenie terminu "ante quem". Jeden $z$ nich, to eragment zapink1/fibula/ do spinania szaty. Zapinka wyliconana jest z brazowej blachy, znaleziona w Beocj1, najprawdopodo bniej w Tebach, datowana na plerwsza, lub 2. poz. VIII w. prz.Chr.., lub na jego koniec /ok. $700 \mathrm{prz} . \mathrm{Chr} . /$. Na zachowanym eragmencie wyryty jest kón na czterech kółkach, z czterema prostokątnymi oknami w boku ${ }^{7}$. Nie ma wiec żadnej watpliwośc1, ze artysta wyobraz1l w ten sposób konia trojańskiego z otworami prowadzącymi do kryjówki greckich mojowników.

Drugi przedmiot jest późniejszy, ale o nieporównanie wyzszej wartośc1 artystycznej 1 dokumentalnej. Jest to ogromna amfora gl1niana $z$ wielopasowa dekoracja figuralna, nie malowana lecz reliefowa, odkryta przed dwuiziestoma laty na wyspie Mykonos. Specjaliśc1 od ceramiki cykladzkiej datuja ja zgodnie na ok. 670 r. prz.Chr. W pasie figuralnym zdobiącym szyje naczynia przedstawiony jest kor na kółkach z pięcloma otworami w boku 1 dwoma w szy 1 . Co olekawsze, ze wszystkioh otworów wychylaja sie wojownicy wyrzucajacy broń, a Inni, Już uzbrojeni, gromadza się u nóg konia. Dzięk1 wprowadzeniu nienaturalnych proporcji między koniem 1 ludími artysta uzys-

6 Proclos, cer Epicorum Graecorum Fragmenta, ed. G.Kinkel, LIpsiae 1877, vol.1,37,49; Pseudo-Apollodoros, Epitome 5, ed. Loeb, Classical Library/voi. 122,130\%.

7 K.Fittschen, Untersuchungen zum Beginn der Sagendarstellungen bel den Grieohen, Gottingen 1969, 182, Nr 98; British Museum 3205. 
kał pozadany efekt. Dla oglądającego dekorację naczynia oczywiste jest, ze ma przed sobą nie zwykłego konia, lecz trojańskiego kolosa w kstałcie konia ${ }^{8}$.

Przyjøując za słuszne datomanie ribuli beockiej na ok. 700 prz.Chr., a amfory cykladzkiej naok. 670 prz.Chr., naleźy stwierdzić, ze wierwszej ćwierci VII w. prz.Chr. mit o trojańskim koniu był Juź znany weocj1 1 na Cykladach. Oznacza to, ze wówczas "Odyseja", czy raczej treśc "Odysei" była juz rozpowszechniona na wyspach 1 na lądzie greckili. Poemat uusiał więc powstać nieco wczé́niej, przed końcem VIII w. Jeśl1 nawet oba nyzej omóvione wyobrazenia sa llustracjami nie "Odyse1", lecz poematóv pohomerycicich, co też jest prawdopodobne, to nie zakłóca to naszego rozumowania w sprawie daty najstarszej wersjl mitu.

IV sztuce greckiej VI 1 V w. stale przedstawlano ten sam epizod opowiadania o konlu trojarisisia. Ustallz sie wizo perien schemat scony. Wyobrazano zazwyczaj konia na kółkach, widocznego w profilu, z otworari, lub klapani uchylonymi w boku. Z tych otworów wygląaJa, wyrzucaja broí, wyskakuja, lub opuszczajiz sie po uznurzo wojownicy. W najbardziej rozwinietej formie występuja takze grupy Greków juz uzbrojonych, maszerujacych $\mathbf{k}$ kierunku Trojan, a nawet rozpoczynajacych już dzieło zagłady. Niewatpliwie do popularności tego motywu w sztuce przyczyniła sie nie tylko "Odyseja" 1 poemat Arktinosa, lecz także utwór późniejszy, "Zagłada Tro1" Stesichorosa. Nie sposób więo stivierdzić, do którego z trzech poematów-odnieść nalezy malowldła na wazach greckich, korynckiej 1 attyckief z lat 560$550^{9}$.

Najprawdopodobniej w tym sanym czasie powstazo najstarsze małowldło tablicowe /obraz na drewnie/ przedstawlające pozar Tro1, peqdzla Kleanthesa z Koryntu ${ }^{10}$. Zdobilo ono wraz z drugim obrazem Narodziny Ateny/ śwl.ttynie Artemidy Alfejońskiej w poblizu olimpil.

8 K.Fittschen, dz.cyt., 182-183, Nr 99, Museum Mykonos.

9 Por. Aryballos koryncki, K. Schefold, Frtigriechische Sagenbilder, Munchen 1964,88, 11.39; fragnent wazy czarnofigurowej attyck1eJ, tanze, II 254-255, 11. 341; Berlin Zachodn1, Staatilches Museum, Antike Abteilung, F 1723.

10 T.Tosi, Studi archeologiel e letterari sull'Illou Persis, Firenze 1957, 37. 
Niewiele jednak można wyciągnąć informacji na ten temat z licznych wprawdzie, ale skapych wzmanek ${ }^{11}$. 0 wlele lepiej jest nam znane słynne malowidło Polignota, "Zagłada Illonu"/IIlupersis/ wykonane krótıo po 458 r. 1 zdobiące Lesche Knidyjczyków w Delfach. Pauzaniasz opisał je dokładnie, lecz interesujacy nas motyw zaledwie zasygnalizował nadmieniajac, it artysta urydatnit rozmiar trojańskiego konia ukazując jego głowę stercząca powyżej murów iniejakich ${ }^{12}$. Jak popularny był ten motyw w starozytności niech świadczy rakt, ze Petroniusz wkłada w usta zwiedzających nieokreśloną blizej pinakotekę waśnie opis obrazu "Zagłada Tro1"13. Był on zupełnie Inaczej skomponowany, niz ten $\nabla$ Delfach. Koń trojański zajmowaz honorowe, centralne miejsce występując w trzech scenach: budowania, wprowadzania do Tro1, opuszczania kryjówki znajdującej sie w jego brzuchu przez bohaterów. Obraz ten powstał nie wcześniej, niż w IV w. prz. Chr., bo dopiero wówczas zaczęto przedstawiać, 1 to w różnych wersjach skomplikowany epizod wprowadzania drewnianego konia do miasta. Do tej kwestil jeszcze powrócimy, a na razie omówić wypada diva interesujące konte trojańskie odlane z brązu, znane tylko z opisọ́ 1 z napisów na ocalałych szczęśliwym trafem bazach.

Krótko przed 414 r. prz.Chr., artysta Strongylion wykonał na zamówienie Chairedamosa z Koile pomnik wotywny ustawiony w sanktuarium Artemidy Braurońskiej na ateńskiej akropoli ${ }^{14}$. Koń byı dwa 1 pół raza wiekszy od naturalnego, a $z$ otworu w jego boku wychyla11 sie czterej bohaterowie: dwaj synowie Tezeusza/Akamas 1 Demofoon/ Menesteusz 1 Teukros. Te Imiona wymagaja głębszej analizy. W źródłach literackich występuja bowlem imiona odaienne. Wg Ilomera w kryjówce siedzieli: Odyseusz, Antikles, Diomedes, Menelaos, Neoptolemos, wg Wergiliusza: Ulisses, Menelaus, Neoptolemus, Akamas, Epeus, Machaon, Sthenelus, Thoas 1 Tisandrus. Lesches wreszcio wymienta tylko Sinona. Jeśli dokonamy zestawlenia trzech spisów/wg Homera, Wer-

11 Por. Athenaios VIII $346^{\mathrm{b}}$; Strabo, Geographica VIII 3,12; Demetrios Skepsios, Trotkos diakosmos VIII; Plinius, Historia Natural1s XXXV 15.

12 Periegesis $x$ 26,2.

13 Satiricon 89,4-65, tłum. M.Brożek/Petroniusz, Satyryk1, Frocław 1968/106-108: "Ale widz , żeś cały ugrzasł wymobrazie, który przedstawia zdobycie Troi. Spróbuje więc to dziejo objaś-
ní́ ci w wierszach.

14 Arlstophanes, Aves 1128-1130; Pausanias, Perlegesis X 26,2; 
glliusza 1 Pauzaniasza/ to stwierdzimy, ze na ateńskim pomniku figurowały aż trzy osoby nie mymieniane wíródłach literackich. Byli to trzej Ateńczycy: Demofoon, Menesteusz 1 Teukros. Nalezy przypuszczać, że Strongylion dzlałał zgodnle z zyczeniem klienta przedstawiając wyłącznie Ateńczykór, chos nie flgurowall on1 w źródłach 11terackich. W ten sposób wyolbrzymiano loh zasługi w wojnie trojarskiej, a takze uwydatniono dzielnośc, albowiem zarówno Homer, Jak jego epigoni podkreślali, ze do ukrycia w koniu wybraṇi zostall AchaJowie najdzielniejsi. Tak tendencyjne wyobrażenie tłumaczy oię okolicznościami. Pointk ustawiono zapewne w tym samym roku, w którym wystawiona została trylogia trojańska Eurypidesa $/ 415$ r. prz.Chr./. Byz to rok waznych wydarzeń w toczacej sie juz od dawna wojnie peloponeskiej. Zapewne wizerunek Ateńczyków, zwycięzców nad Troja, miał stanowić dobry omen dla Ateńczyków walczących ze Sparta.

Z mojna peloponeska $w$ sposób bezpośrednl był tez związany drugl pomnik konta trojańskiego, także z brazzu, po którym podobnie jak poprzednio pozostal opis Pauzaniasza 1 baza z napisem 15 . Było to wotum dziękczynne Argejczykóv ofiarowane Apollonowi Delfickienu, ufundowane $z$ zupów zdobytych na Sparcie do $414 \mathrm{r}^{16}$ Wykonawca był rzéblarz argejski Antylanes. Nozna wlęc stwierdzić, ze renesans zainteresowań mitem o koniu trojańskim, przypadający na schyłek $V$ w. prz. Chr., miał podłoze historyczne.

W IV w. pojawia sie w sztuce greckiej wcześniejozy epizod tego samego mitu, a mianowicie znalezienie konia przez Trojan przed murami miasta 1 perypetie zwizzane z wprowadzentem go na "arx", przed śwlątynle Ateny. W literaturze epizod ten wystepuje w kilku wersjach. Poświęcimy im nieco uwagi, gdyż 1 w tym przypadku wyobrazenia w stuce moga rzucié śwlatło na tré́c zaginionych poematów.

Wg Homera Trojante znaleźl1 opustoszałym greckim obozie drewnianego konia 1 sami wprowadzil1 go na "arx". Po dyskusji, w której padały projekty zniszczenia tajemniczej konstrukcji, postanowiono

Inscriptiones Graecae, ed. minor, I 535.

15 Pausanias, Periegesis X 9,6; Fouilles des Delphes III 1,385-386. 16 G.Lippold, Griechische Plastik, Munchen 1950, $189,217$. 
zostamíc ja - przed śwlątynią jako dar dla bogów. Ukrytym1 w koniu ludźm dowodził Odyseusz 1 on zadecylowat w nocy o otwarciu kryjówki, opuszczeniu jej 1 rozpoczęciu dzieła zagłady. Wersja Leschesa / ig Proklosa/ Jest odmienna. Trojanie, aby wprowadzic konta do mlasta musiell zburzyć częśc1owo mur 1 uczynili to wbrew gwaztownym protestom Kasandry. Następnie, przekonan1 o zwyc1 zstw1e, zaczęli ucztować. 0 północy z konia stojącego na akropoli wyszedz Sinon 1 dal greckiej flocie sygnal powrotu.

W poemacie Arktinosa watek mitu jest podjety od momentu, gdy Trojanie naradzaja się, co z koniem uczynić. Ten poeta wzbogaca wersje Homera $i$ Leschesa o protest Laokoona 1 jego okrutną émieró wraz z jednyla tylko synem.

Obszerniejsze niz Proklos streszczenie, najprawdopodobulej tych samych poeinatów cyislicznych, pozostawiz Apollodor ${ }^{17}$. W tej wersji na pomysz budory konia wpadł Odyseusz, ale na wykonawce powołał Epeusa, albowiem ten był architektem/por. wyzej/. Odyseusz kazal Grekom spalić obóz, a na kontu wyryć nap1s: "Za powrót do domu Hellenowie /składają/ Atenie dar". Nawiasein mówląc ten pomysł przyjął sle w literaturze rzymskiej, albowiem taki napis uzasadniał w sposób loglezny/bez cudownoścl 1 lantazj1/, dlaczego Trojanle wprowadzili konia do sanktuarium bogini. Poitarza go w laciriskim brzmieniu L.Akcjusz $\approx$ tragedil "Deiphobos"18 oraz Hyglnus w krótszej redakcj1 ${ }^{19}$. Wracajmy Jednak do cykl1ków wg Apollodora. Wersja jest w zasadzie zgodna ze streszczeniaml Proklosa/protest Kasandry, Laokoona, wezwanie ploty greokiej przez Sinona/ z wyj:ktkien jednego szczegółu: Trojanle wprowadzaja konia przez bramę nle rozbierając muru.

Treść poematu Leschesa mozna ostatecznte zweryfikować na podstawle płaskorzeźb na marmurowej płytce zw. "Tabula Illaca Capito11na" 20 . Jak bowiein głosi objaśniajaca inskrypoja, wydarzenia opisane "Małej Illadzie" przedstawiz artysta wg Leschesa/a treść

17 Apollodoro8, Epitome 5, 14-21.

18 O.Ribbeck, Tragicorum Homanorum Fragnenta, Lips1ae 18712, 152: "Minervae donum armipotentes Danai abeuntes dicant".

19 Fabularum liber 108: "Danal Minervae dono dant".

20 A.Sadurska, Les tables 111aques, Warszawa 1964, 24-27, Nr 1, 
"Il1ou pérsis" mg Stesichorosa/. "Małej Iliadzie" poświęcona jest cała serla scen tworzacych jeden wydzielony fryz. Należy do nich protest Kasandry stojącej przed Bramą Skajską, Sinon prowadzony Jako jeniec przed Priamem, Priam wskazujący ludziom ciągnącyn konia Branę Skajska 1 wreszcie orszak złozony z dwóch tancerzy 1 dziesięciu osób/Trojanie 1 Trojanki/clągnącyoh drewnianego konia. W murze obok bramy widać wyraźnie duży wyłom.

Jedyna odmiana w wersj1 Vergiliugza, to długa opowieśó Sinona tłumacz zcego Prlamowi rzekomy pomysł Kalchasa złożenia bogom na ofiarę jego Sinona oraz rzekoną przepowiednię Kalchasa dotyezącą bezpośrednio drewnianego konta. Wprowadzenie tego monstrum do Trod zapewnić ma miastu ostateczne zwyciostwo. Ta wersja uzasadniaia pomyłke 1 fatalną decyzje Priama, którego rzynski poeta pragnaz przedstawíc w jak najkorzystniejszym świetle. "Tabula Illaca Capitolina" jest niemal współczesna "Eneidzie". Porównanie wyobrażonych na niej scen z tekstem Firergiliusza pozwala stwiordzić duza zależnośc poety od poematu Leschesa. Nie jest wykluczone, ze 1 wykonawca płaskorzeźb/Teodoros z Samos/ I Werglliusz korzystaliz tego samego stresz czenia, albowien oryglnalny tekst juz wówczas zapenne uległ zapomnieniu.

W sztuce greckioj epizod wprowadzania koni do Trol pojawial sie tylko sporadycznie w IV-II w. prz.Chr. Należał natomiast do motywów szczególnie lubianych w państwie rzymskim. Podobnie jak na "Tabula Iliaca" jest on wyobrażany $/$ postaci serii scen rozgrywających sie pod murami, poblizu Bramy Skajskiej. W scenach tych występuje Priam, Kasandra, sporadycznie zaś Sinon, Hekuba, Helena. Koń umieszczony jest na platformie na kółkach, często paradnie przystrojony, clagntęty przez grono Trojan na linach. Towarzyszy mu niekiedy orszak rozradowanych mleszlsaniców Tro1. Wyobrażenia te występują w I-II w. 1 niemal wszystkie sq póniejsze od "Eneidy", a więc zależne bezpośrednio od poenatu lací́sklego, lub od 1lustracjl zdobiących zwoje z jego tekstem.

Warto zauważyć, ze podobnie jak Grecj1 w czasie wojny peloponeskiej, tak w Rymie $v$ okresie Augusta nastąpiło wyraźne skoncentrowanie uwagl na micie o konlu trojaúskim. Trumaczy się ono w podobny sposób, a mlanowicie na gruncie wydarzeń historycznyoh. Juliusz Cezar 1 jego astęca wykorzystywall do celów politycznych legendę 
- Eneaszu 1 Askanluszu, załozycielach Lavinium 1 Alba Longa, a więc mitycznych protoplastach Romulusa. Nadto Askaniusz zwany takze Julusem miał być założycielem rodu julijsklego, przez oo Juliusze zyskiwal1 pokrewleństwo z boginia Wenus ${ }^{21}$. Najprzód Cezar, a następnie August sprawujaco $w$ nzymie mecenat artystyczny upowszechniał mity trojaxiskie. Fyrazem tej polityk1 w sztuoe monumentalnej sa płaskorzeźby 0łtarza Pokoju na Polu Marsowym mymie, ale podobne motywy wystepowały wekoracji wielu budowli publicznych oraz na monotach, a te były w starozytnosci najpotęziejszym srodkiem masowego przekazu. Usilna propaganda przyniosła spadziewane rezultaty. Sceny z wojny trojańskiej, a wśród nich wprowadzanie do Troi drewnianego konla zdobla liczne wnętrza domów mieszkalnych, a także występuja w sztuce sepulkralnej, Jako malowidka wrobowcach 1 płaskorzeźby na sarkofagach w I-II $w$. Jak bardzo mit ten by $\$$ Rzymie popularny moze świadczyó fakt, ze Petroniusz pragnąc wykazać bezbrzezna 1gnorancje negatywnego bohatera swojej opowieśc1 wkłada w usta Trymalch1c na zdanie o srebrnym kubku: "ubi Daedalus Niobam in equum Trolanum Includit $n^{22}$.

Sceny z tego mitu spotyka sie takze poza Italiz. Drewniany koń figuruje na malowanej tarczy znalezionej w Dura Europos w Syr11, na ściennym fresku z Hermoupolis $w$ Egipcie 1 nawet na płaskorzeźbie z Gandhary/Pakistan/23. Tak szerok1 zasięg motywu mógłby budzić zdziwienie, ale sprawę wyjaśnia zabytek z Dura Europos. W miescie tym w 165 r. został załozony rzymsk1 obóz wojskory 1 tarcza z pewnościa nalezata do jego mieszkańców. Równiez egipskio malowidło 1 gandharska płaskorzeźba nie były takze przeznaczone dla lokalnych odbiorcóm.

Pod koniec II w. zainteresowanie mitem wyraznie wygasa. Oba epizody /scena pod nurami 1 scena wro1/ I1guruja natomiast wśród

21 A.Sadurska, La politique dynastique d'Auguste et l'art de son temps, "Ltudes et Travaux" 3/1969/ 94-106.

22 Satiricon, 52,2.

23 Ch.Dawson, Romano-Campantan Mythologlcal Painting, London 1944, $85, \mathrm{Nr} 12, \mathrm{pl} .4 ; 86, \mathrm{Nr} 13, \mathrm{pl} .5 ; 156 ;$ G.Koch, Romische Sarkophage, Berlin 1982, 154 a-d; M. iostovtzeff, The Excavations at Doura Europos. Preiliminary Heport, Lond on 1939, 332-337, pl. 42, Zabytek $w$ Yale University, Galery of Fine Árts; Kaír, Museum Archeologicum 63611; K. We1tzmann. Ancient book 11 lumination, Cambridge 1959, pl.23, 11.55 . 
llustracji "Eneldy". Szczęśliwym trafem w dwóch najstarazych zachowanych kodeksach znajdują się dwie rózne llustracje ${ }^{24}$. W kodeksie "Vergilius Romanus" z IV w. przetrwała minlatura ze scena wprowadzania konia do Tro1, a wodeksie "Vergilius Vaticanus" z V w. - obraz zagłady miasta. Ta ostatnia ilustracja zawiera motyw szczególnie drastyczny i rzadko przedstawiany, a mianowicie mordowanie Trojan zaskoczonych przy uozcle lub we śnie.

Na zakończenie nalezy wyjaśnić dlaczego w sztuce greckiej przedstawiano chętniej ostatni epizod mitu utrwalony wszak pędzlem najwybitniejszego iualarza, 1 jak siz wydawało uwieczniony w brazie, podczas gdy if sztuce rzyıskiej o wiele większz popularnoś́ zysicała mniej efektowna scena pod murami Tro1. Otóz sądzę, ze na ten ostatni wybór miała duży wpływ duma narodowa obywateli rzymskich. Rzymianie uważajz̨o się za potomków Trojan, a takie przekonanie zostało 1m wpojone, nie mogli cieszyć się z obrazu klęski mlasnych przodków. Natomiast wprowadzenie konia do Tro1 było tej klęski zaledwie prologieı. Scena ta pozwalała ponado przedstawić Priama w całym majestacle 1 Kasandre $w$ patetycznoj pozie gwałtomnego protestu. Równocześnie zaś Grek Sinon, przykładowy wiarołomca, wyobrazany był na wzór jeńca, ze skrępowanymi na plecach rękami. Dla kzymian by to na pewno przyjemniejszy widok od obrazu zbrojnych Greków mordujących bezbronnyoh Trojan. Zauważy, ze nie l naczej przedstawia sie sprawa w twórczości literackiej. Homer, przy całym swoim obiektywizmie raduje się przewagami Achajów, a w osiemset lat pónín Wergiliusz rozpacza nad zagladą Troi.

Wypada więc stwierdzić na zakończenie, ze zarówno w Grecji, Jak w Mymie motywy mitologiozne w literaturze 1 sztuce były doblerane, a następnie modelowane zgodnie z potrzebami nie tylko kultu, ale 1 układów politycznych.

Anna Sadurska - UW Warszawa

24 K. Weltzmann, dz.cyt., 60-61, 11.69,68; Bibllotheca Vaticana, Codex lat. 3867,3225 . 


\section{CheVAL TROYEN \\ ORIGINE, EVOLUTION ET DIFFUSION DU MYTHE DANS L'ANTIQUITE}

Le mythe a f́té probablement une invention originale congue par l'auteur de l'Odyssée, Le prototype du cheval colossal de-bois, bât 1 et non sculpté, est á chercher parmi les bâteaux archaliques, à proue décorée d'une protomé ohevaline. Les plus anciens objets a I Image du cheval troyen permettent de préciser un'terminus ante quem'de l'Odyssée, à savoir à la fin du virie s.

Les scenes à l'lmage du cheval troyen se partagent en 2 groupes 1/ épisode de la "Petite Iliade", en dehors de la vilie, 2/ épisode de $1^{\prime} I l i o u p e r s i s$, dans 1 enceinte. L'a. prouve, que le premier groupe dépendait du poème de Lesches, qui a aussi infiuencé Virgile. La diffusion des deux schémats lconographiques n'était point ṕarailèle. Cheval troyen rempli des guerriers grecs, à cachotte ouverte appartenait aux motifs préférés des artistes grecs, surtout au temps de la Guerre de Péloponnèse, en tant que syiabolo de la victoire. Les Romalns cholsissaient volontiers l'introduction du cheval troyen dans la ville de Trole/preuve de la ruse greoqué/ en présence des héros troyens. Le motif a gagné sa popularité grâce à la propagande dynastique d'Auguste, qui englobalt la légende troyenne des origines de Roine.

Conclusion: la diffusion du mythe dans 1 art et la littérature, en Grèce et à Rome, dépendait des circonstances et des raisons politiques. 